\title{
Ja zum gesunden Menschenverstand, nein zum Dogmatismus
}

\footnotetext{
* Kollege Daniel Beutler, der sich zu seiner Suchtvergangenheit bekannt hat, ist Mitglied des Referendumskomitees. Er ist nicht der einzige ehemalige Abhängige, der nach Befreiung von seiner Sucht zum Verfechter besonders strenge Positionen wird. Diesen Menschen mit ihrem unweigerlich schweren Lebensweg gilt mein höchster Respekt, jedoch sind sie nicht die Mehrheit, und man kann eine ausgewogene Politik zum Wohle der gesamten Gesellschaft nicht auf die Überzeugungen gründen, die Einzelne aufgrund ihrer persönlichen Vorgeschichte vertreten. Vielmehr spricht dies für die Notwendigkeit, ein breitgefächertes Spektrum an Angeboten bereitzuhalten.
}

1 Romann C. Drogenpolitik: Ja zum Bewährten, kein Konsens beim Neuen. Schweiz Ärztezeitung. 2008;89(37):1569

2 Hampton T. Abstinence-only programs under fire. JAMA. 2008; 299:2013-5
Christine Romann, Mitglied des Zentralvorstands, nennt es sehr treffend eine «ideologisierte, zu nichts führende Debatte» [1] - ich für meinen Teil habe sie zur Genüge miterlebt. In meiner langjährigen Tätigkeit im Gesundheitswesen, in der auch die Prävention und Bekämpfung der Drogenabhängigkeit zu meinen Aufgaben gehörten, war es mein Langzeitprojekt, mich hier mit den praktizierenden Kollegen für Vernunft und Pragmatismus einzusetzen. Bisweilen mit Rückschlägen, denn diese Bemühungen waren nicht immer von Erfolg gekrönt, was insbesondere dem Einfluss realitätsferner, doktrinärer Meinungen zu verdanken war, die teilweise an geistigen Terrorismus grenzen und von selbsternannten, ideologische Ziele verfolgenden Experten stammen. Diese Kreise sind gegen die geplante Revision des BetmG, obwohl sie von Vernunft geprägte Neuerungen beinhaltet, die sich auf wissenschaftliche Nachweise und empirische Belege stützen, die die notwendige Bestätigung für die Richtigkeit des eingeschlagenen Kurses der Vier-Säulen-Politik erbringen.

Auf alle diese Änderungen im Einzelnen einzugehen würde den Rahmen dieses Beitrags sprengen (nachzulesen im Internet unter www. betaeubungsmittelgesetz.ch). Ein Aspekt, der die ärztliche Tätigkeit betrifft, soll jedoch erwähnt werden: Die Literatur belegt, dass Cannabis in ausgewählten Indikationen einen echten Beitrag zur Schmerzlinderung leisten kann. Das erneuerte Gesetz würde diese Therapieform zulassen, doch die Hardliner, die dem unseligen amerikanischen Vorbild des «War on Drugs» nacheifern, sind dagegen, die Schweizer Patienten von diesem Fortschritt profitieren zu lassen.

Ein anderes Thema ging gerade durch die Presse: Mit Erstaunen verfolgen wir die Verrenkungen, die die US-Republikaner angesichts der Widersprüche vollführen, die zwischen ihren rigorosen Ansichten und dem echten Leben klaffen. Zum Beispiel, wenn es um die Schwangerschaft der jugendlichen Tochter von Sarah Palin geht. Enthaltsamkeit vor der Ehe ist einer der Leitsätze, die die selbsternannte «Christliche Koalition» ihren Mitbürgern gern aufzwingen würde. Ein aktueller Artikel aus der JAMA [2] belegt jedoch, dass Enthaltsamkeitskampagnen allein «absolut keine messbare Wirkung auf das Alter beim ersten Verkehr, die Anzahl der Sexualpartner, die Schwangerschaften oder sexuell übertragbare Erkrankungen» haben. Solide internationale Studien haben hingegen ergeben, dass junge Menschen, die adäquat und ohne erhobenen Zeigefinger aufgeklärt wurden, später und seltener Sex haben und sich dabei besser schützen als ihre Altersgenossen, die keine solche Aufklärung erhalten haben. Genauso ist beim Thema Drogen objektive Information mehr wert als blindes Verteufeln, das für die jungen Menschen nicht glaubwürdig ist.

Ich bin dafür, dass alle Suchtkranken (einschliesslich Alkohol- und Tabaksüchtige) die Möglichkeit erhalten, sich von ihrer Abhängigkeit zu befreien, und zwar mit Mitteln, die auf ihre persönliche Lage und ihren Gesundheitszustand zugeschnitten sind. Die Erfahrung zeigt, dass es unerlässlich ist, mit einer Vielfalt von Methoden vorgehen zu können, die jeweils im richtigen Moment angeboten werden (kein Fachmann kann heute ernsthaft behaupten, dass es eine «einzig wahre» Vorgehensweise gibt).* Das dogmatische Beharren auf absoluter Abstinenz allein stellt bei illegalen Substanzen ebenso wenig eine Lösung dar wie bei Jugendsexualität.

Massnahmen, die mit «Tunnelblick» nur auf Abstinenz und Repression abzielen, werden nicht dazu beitragen, das Drogenproblem in den Griff zu bekommen. Es ist falsch, die Augen vor dem zu verschliessen, was unsere Gesellschaft seit 40 Jahren durchlebt - wir brauchen die Klugheit und den politischen Mut, genau dies zu berücksichtigen. Die Aufgabe der Ärzte ist es bekanntzumachen, dass eine Politik der «reinen Tugend», wie die Gegner des BetmG sie sich wünschen, absolut nicht wünschenswerte Konsequenzen hätte, sondern Bestrafung, Ausgrenzung und Krankheit bedeuten würde: steigende Infektionsraten, noch stärkerer Verfall derjenigen, die vorübergehend nicht in der Lage sind, anspruchsvolle Vorschriften einzuhalten, und zunehmende Kriminalität. Wollen wir das? Die Revision des Betäubungsmittelgesetzes muss angenommen werden.

Dr. med. Jean Martin, ehemaliger Kantonsarzt Waadt und Redaktor der SÄZ 